\title{
Intrasession repeatability of biometric measurements obtained with a low coherence interferometry system in pseudophakic eyes
}

\author{
Hideki Fukumitsu, Vicent J Camps \& David P. Piñero
}

To cite this article: Hideki Fukumitsu, Vicent J Camps \& David P. Piñero (2019): Intrasession repeatability of biometric measurements obtained with a low coherence interferometry system in pseudophakic eyes, Current Eye Research, DOI: 10.1080/02713683.2019.1659976

To link to this article: https://doi.org/10.1080/02713683.2019.1659976

Accepted author version posted online: 22

Aug 2019.

Submit your article to this journal

Q View related articles $\asymp$

View Crossmark data $₫$ 
Publisher: Taylor \& Francis

Journal: Current Eye Research

DOI: $10.1080 / 02713683.2019 .1659976$

INTRASESSION REPEATABILITY OF BIOMETRIC MEASUREMENTS

OBTAINED WITH A LOW COHERENCE INTERFEROMETRY SYSTEM IN

PSEUDOPHAKIC EYES

Running head: Optical biometry consistency in pseudophakic eyes

Hideki Fukumitsu, $\mathrm{MD}^{1,2,3}$

Vicent J Camps, $\mathrm{PhD}^{1}$

David P. Piñero, $\mathrm{PhD}^{1,2}$

From:

${ }^{1}$ Department of Optics, Pharmacology and Anatomy, University of Alicante, Spain

${ }^{2}$ Department of Ophthalmology. Vithas Medimar International Hospital, Alicante, Spain

${ }^{3}$ Department of Ophthalmology, Marina Baixa Hospital, Villajoyosa, Alicante, Spain

\section{Corresponding author:}

Dr David P Piñero

Department of Optics, Pharmacology and Anatomy. University of Alicante. 


\author{
Crta San Vicente del Raspeig s/n \\ 03690 San Vicente del Raspeig, Alicante (Spain) \\ Telf.- +34965903400 \\ E-mail: david.pinyero@ua.es
}

Financial disclosure:

The author David P Piñero has been supported by the Ministry of Economy, Industry and Competitiveness of Spain within the program Ramón y Cajal, RYC2016-20471. 


\begin{abstract}
Purpose: To evaluate the intrasession repeatability of the biometric measurements obtained with a low coherence reflectometry optical biometer in pseudophakic eyes implanted with two different types of intraocular lens (IOL).
\end{abstract}

Methods: Prospective, single-center, comparative study including 69 eyes of 69 patients with ages ranging from 51 to 92 years. Previous uncomplicated cataract surgery had been performed in all patients 1 to 2 months before measurements, with implantation of the Acrysof SN60WF IOL in 35 eyes (35 patients, group 1) and the IOL Akreos MI60 in 34 eyes (34 patients, group 2). A complete postoperative ophthalmological examination was performed including three consecutive measurements with the "Aladdin" system from (Topcon, Japan). Intrasession repeatability of axial length (AXL), anterior chamber depth (ACD) and IOL thickness (IOLT) was assessed with the within-subject standard deviation $\left(\mathrm{S}_{\mathrm{w}}\right)$, intraobserver precision (1.96 $\left.\times \mathrm{S}_{\mathrm{w}}\right)$, coefficient of variation $(\mathrm{CV})$ and intraclass correlation coefficient (ICC). Results: The $\mathrm{S}_{\mathrm{w}}$ for AXL measurements was 0.03 and $0.05 \mathrm{~mm}$ in groups 1 and 2, respectively, with ICC of 1.000 and 0.999 (CV: 0.14 and $0.22 \%$ ) $(p \leq 0.031)$. Concerning pseudophakic ACD, the $S_{w}$ was 0.03 and $0.09 \mathrm{~mm}$ in groups 1 and 2, respectively, with ICC of 0.992 and $0.956(\mathrm{CV}: 0.55$ and $1.75 \%)(\mathrm{p} \leq 0.021)$. The variability of IOLT measurements was high in both groups, with $\mathrm{S}_{\mathrm{w}}$ of 0.12 and $0.29 \mathrm{~mm}$ for groups 1 and $2(\mathrm{p}=0.008)$, respectively, and ICC of 0.065 and 0.770 (CV: 20.84 and 62.39\%).

Conclusions: The optical biometer "Aladdin" (Topcon, Japan) provides consistent measurements of AXL and ACD in pseudophakic eyes. However, there is a limitation in the consistency of IOLT measurements that should be investigated further. 


\section{Introduction}

In 1999, the IOL-Master system was introduced as the first optical biometer capable of measuring several variables of the eye with better repeatability and accuracy than the contact ultrasonographic technique. ${ }^{1-3}$ In short time, it became the gold standard for intraocular lens (IOL) power calculation in patients undergoing cataract surgery. ${ }^{4,5}$ Since then, a great variety of optical biometers have been developed and commercially released, which have been validated in terms of accuracy and repeatability in different studies. ${ }^{6-9}$

One of the recently developed optical biometers is the Aladdin system from Topcon, which is based on low coherence interferometry. This device has shown to provide reproducible and repeatable anatomical measurements in healthy and cataract eyes. $^{10,11}$ Likewise, the interchangeability of Aladdin biometric data with those obtained with the optical low coherence reflectometry-based system Lenstar (HaagStreit, Koniz Swiss), ${ }^{12}$ the partial coherence interferometry-based biometer IOLMaster 500 (Zeiss, Oberkochen Germany), ${ }^{13-15}$ and the intraoperative image-guided system Verion (Alcon Laboratories Inc, Fort Worth, Texas, USA) ${ }^{16}$ has been analyzed, confirming the good agreement between devices. However, to our knowledge, no studies have been conducted to evaluate the reliability of biometric measures obtained with the Aladdin system in pseudophakic patients. It should be considered that optical biometric measurements in pseudophakic eyes, especially anterior chamber depth, could be of great importance to calculate IOL power in piggyback lenses as well as to characterize the effective lens position (ELP) of a specific IOL type, allowing then an optimization of IOL power formulas. 
The aim of the current study was to evaluate the intrasession repeatability of the biometric measurements obtained with the low coherence reflectometry system Aladdin in pseudophakic eyes implanted with two different types of IOL.

\section{Material and Methods}

\section{$\underline{\text { Patients }}$}

A total of 69 eyes of 69 patients with ages ranging from 51 to 92 years were included in this prospective, single-center, comparative study. All subjects were selected from the cataract consultation of the Department of Ophthalmology of the Marina Baixa Hospital (Villajoyosa, Alicante, Spain) where this investigation was developed. Only one eye from each subject was chosen for the study with a simple random sampling method (randomization table) in order to avoid the potential interference of the correlation that often exists between the 2 eyes of the same person. Inclusion criteria were age above 40 years and patients with previous phacoemulsification surgery with IOL implantation between 1 and 2 months before the examination corresponding to this study. Exclusion criteria were previous corneal refractive surgery, corneal opacities or scars, active ocular disease, YAG capsulotomy due to posterior capsular opacification and patients that suffered complications during surgery (capsular tears and anterior vitrectomy). Before being included in the study, all patients were informed about the aim of the study and signed an informed consent. The study methods adhered to the tenets of the Declaration of Helsinki and was approved by the hospital ethics committee. 


\section{Ocular examination}

All clinical measurements were performed between 1 and 2 months after uncomplicated cataract surgery. A comprehensive ophthalmological exam was done that included measurements of uncorrected and best corrected visual acuity, manifest refraction, air tonometry, corneal endothelial cell count, slit-lamp biomicroscopy examination, and corneal topography and non-contact biometry with the Aladdin system. A single experienced examiner (HF) performed all biometric measurements in the morning period, between 8:30 to 15:00 hours. In all cases, three consecutive ocular biometric measures were obtained using the pseudophakic mode of the device to assess the level of intrasession repeatability of axial length (AXL), anterior chamber depth (ACD) and IOL thickness (IOLT).

\section{Optical biometer}

The Aladdin is an optical biometer and topography system that combines lowcoherence interferometry and Placido-disc topography technologies to obtain a series of anatomical measurements, including AXL, ACD, pupillometry, white-to-white corneal diameter, lens thickness and anterior corneal geometry. The technology of low coherence interferometry enables the biometer to obtain AXL measurements in the range from 15 to $38 \mathrm{~mm}$, with high signal-to-noise ratio using the super luminescent diode of $850 \mathrm{~nm}$, with the possibility of signal processing even in highdensity cataracts. In addition, AXL measurements can be also performed in pseudophakic, aphakic, and silicone oil-filled eyes. Concerning the corneal topography system, it uses the reflection of a set of 24 Placido rings, allowing the measurement of more than 6,200 points covering up to $9.8 \mathrm{~mm}$ of cornea. 


\section{Intraocular lenses}

In this study, only eyes implanted with two different types of IOL were evaluated. One of these two IOLs was the MI60L Akreos MICS from Bausch + Lomb, which is a hydrophilic acrylic IOL with UV blocker, refractive index of 1.458 , aspheric optics and overall diameter of $10.7 \mathrm{~mm}$. This IOL has an A-constant of 119.1. The other IOL evaluated was the Acrysof SN60WF IQ from Alcon, which is an IOL made of an acrylate/methacylate copolymer, with UV and blue light filter, refractive index of 1.55, biconvex-aspheric optics, optic and overall diameters of 6.0 and $13.0 \mathrm{~mm}$, respectively, and an A-constant of 118.7 .

\section{Statistical analysis}

The statistical data analysis was performed using the software SPSS version 15.0 for Windows (SPSS, Chicago, Illinois, USA). Normality of all data distributions was confirmed by means of the Kolmogorov-Smirnov test. Then, parametric statistics was always applied. First, intrasession repeatability for AXL, ACD and IOLT data provided by the Aladdin system was assessed according to the following variables: the within-subject standard deviation $\left(\mathrm{S}_{\mathrm{w}}\right)$ of the 3 consecutive measurements, intrasubject precision $\left(1.96 \times \mathrm{S}_{\mathrm{w}}\right)$, coefficient of variation $(\mathrm{CV})$ and the intraclass correlation coefficient (ICC). Differences in terms of repeatability parameters between IOLs were evaluated using the unpaired Student $t$ test. Bland and Altman analysis was used to evaluate the interchangeability of repeated measures of AXL, ACD, and IOLT in each IOL group. Finally, the Pearson correlation coefficient was used to assess the correlation between IOL power and the intrasession variability obtained for each parameter evaluated in terms of $S_{w}$ as well as the correlation 
between the magnitude of each parameter evaluated and its $S_{w}$ associated. The aim of this analysis was to assess if there were cases in which the intrasession error was higher or lower (shorter or longer eyes, eyes implanted with lower or higher IOL powers...). All statistical tests were 2-tailed, and p-values less than 0.05 were considered statistically significant.

\section{Results}

The study involved 69 eyes (34 right and 35 left eyes) of 69 subjects (34 males and 35 females) with a mean age of 72.4 years old (ranging from 51 to 92 years). Two groups of eyes were differentiated according to the IOL implanted: group 1 including 35 eyes of 35 patients implanted with the IOL Acrysof SN60WF, and group 2 including 34 eyes of 34 patients implanted with the IOL Akreos MI60. Table 1 summarizes the main clinical characteristics of patients included in each group. As shown, only statistically significant differences between groups were found in the gender distribution $(p=0.041)$. Likewise, a small in magnitude but statistically significant increase was observed in AXL with cataract surgery in the two groups of eyes evaluated $(\mathrm{p}<0.001)$.

Table 2 summarizes the outcomes of the intrasession repeatability analysis for pseudophakic AXL, pseudophakic ACT and IOLT provided by the Aladdin system in the two groups of eyes of the current sample. The $S_{w}$ in both groups was $0.05 \mathrm{~mm}$ or below for AXL measurements, with ICC of 0.999 or higher. Significantly lower values of $S_{w}$, intrasubject precision and coefficient of variation was found in group 1 compared to $2(\mathrm{p} \leq 0.031)$. This was consistent with the results of the Bland and 
Altman analysis, showing lower limits of agreement in group 1. Concerning pseudophakic ACD, the $\mathrm{S}_{\mathrm{w}}$ in both groups was $0.09 \mathrm{~mm}$ or below, with ICC of 0.956 or higher. As happened with AXL, significantly lower values of $S_{w}$, intrasubject precision and coefficient of variation was found in group $1(\mathrm{p} \leq 0.021)$. As happened with AXL, the results of the Bland and Altman analysis showed lower limits of agreement in group 1. The variability of IOLT measurements was high in both groups, with $\mathrm{S}_{\mathrm{w}}$ of $0.29 \mathrm{~mm}$ or below, ICC of 0.770 or below, and clinically relevant limits of agreement. Significantly higher values of $S_{w}$ and intrasubject precision for IOLT were found in group $2(\mathrm{p}=0.008)$, but no significant differences were found between groups for the coefficient of variation of this parameter $(p=0.368)$.

No significant correlations of IOL power with the following intrasubject parameters were found: $\mathrm{S}_{\mathrm{w}}$ for AXL in groups $1(\mathrm{r}=0.221, \mathrm{p}=0.203)$ and $2(\mathrm{r}=-0.037$, $\mathrm{p}=0.837), \mathrm{S}_{\mathrm{w}}$ for ACD in group $2(\mathrm{r}=-0.241, \mathrm{p}=0.177)$, and $\mathrm{S}_{\mathrm{w}}$ for IOLT in groups 1 $(\mathrm{r}=-0.158, \mathrm{p}=0.441)$ and $2(\mathrm{r}=-0.028, \mathrm{p}=0.891)$. In contrast, a statistically significant correlation was found between IOL power and $S_{w}$ for ACD in group $1(r=-0.490$, $\mathrm{p}=0.003$ ). Concerning the correlation between the magnitude and the $\mathrm{S}_{\mathrm{w}}$ of each variable, only a statistically significant correlation was found between the magnitude of IOLT and its $\mathrm{S}_{\mathrm{w}}(\mathrm{r}=0.671, \mathrm{p}=0.006)$.

\section{Discussion}

Optical biometry has become an indispensable tool in ophthalmological clinical practice, especially if anterior segment surgeries are performed. For this reason, studies evaluating the repeatability and reproducibility of biometric measurements with the different devices that are commercially available are 
necessary to confirm their validity in clinical setting. Despite the great variety of studies performed to this date to evaluate the intrasession repeatability of biometric measurements, ${ }^{1,2,10-12}$ any of them have been conducted in pseudophakic eyes. Indeed, pseudophakic measurements are used in studies assuming that their consistency is equivalent to that assessed in phakic eyes. Previous reports have established that ACD measurements obtained in pseudophakic eyes with partial coherence interferometry and optical low coherence reflectometry can be used interchangeably. ${ }^{17}$ Other studies have confirmed that the agreement of ACD measurements is better in phakic than pseudophakic eyes when comparing Pentacam and ultrasound devices, ${ }^{18}$ optical coherence tomography versus ultrasound biomicroscopy, ${ }^{19}$ and when comparing Pentacam, IOL-Master, and A-scan. ${ }^{20}$ The aim of the current study was to analyze the intrasession repeatability of anatomical measurements obtained with a specific model of optical biometer in pseudophakic eyes implanted with two different types of IOLs. This was performed to confirm the consistency of such measures to be used to optimize IOL power calculation in piggyback cases or in general practice to improve the characterization of ELP. It should be considered that the pseudophakic ACD is a crucial parameter in the calculation of the IOL power to implant in a piggyback mode, ${ }^{21}$ and therefore the consistency of this type of pseudophakic anatomical measures must be tested and confirmed. Likewise, the relationship between pseudophakic ACD and ELP has been investigated, being both parameters significantly correlated. ${ }^{22}$ Therefore, the analysis of changes in pseudophakic ACD can be used to optimize algorithms developed to estimate ELP for different types of IOL as long as ACD measurements are reliable and consistent.

Concerning AXL, $\mathrm{S}_{\mathrm{w}}$ values of 0.03 and $0.05 \mathrm{~mm}$ were found in groups 1 and 2 , respectively, with ICC of 1.000 and 0.999 . These levels of $S_{w}$ were consistent with 
those reported in other studies evaluating the intrasession repeatability of AXL measurements in healthy and cataract phakic eyes with the same optical biometers as well as with other biometric devices. ${ }^{10-12,14,23-25}$ Huang et $\mathrm{al}^{11}$ obtained a $\mathrm{S}_{\mathrm{w}}$ value of $0.02 \mathrm{~mm}$ for AXL measurements obtained with the Aladdin system in healthy and cataract phakic eyes. McAlinden at $\mathrm{al}^{12}$ reported a $\mathrm{S}_{\mathrm{w}}$ value of $0.02 \mathrm{~mm}$ for AXL measurements obtained with the optical low-coherence reflectometer Lenstar from Haag-Strait. Sabatino and colleagues ${ }^{14}$ found in another repeatability study of the biometric measurements provided by the IOL-Master and Aladdin systems values of ICC of 0.997 and 0.998 , respectively. In our study, although intrasession repeatability of AXL measures was good in both IOL groups, a significant difference was obtained, with a trend to more variability in anatomical measurements obtained in pseudophakic eyes implanted with the acrylic MI60 IOL with lower refractive index. This is coherent with the inherent dependency of the variability error of measurements based on optical low-coherence reflectometry on the refractive index of the sample evaluated. $^{26,27}$ However, the variability is not clinically relevant considering the potential variations of the refractive index of IOL materials. Faria-Ribeiro and colleagues $^{28}$ demonstrated that the assumption of a single "average" refractive index in the estimation of AXL using partial coherence interferometry biometry only induces very small errors in a wide range of combinations of ocular dimensions.

Concerning ACD, good levels of intrasession repeatability were found in the two IOL groups with the optical biometer evaluated. Specifically, mean $\mathrm{S}_{\mathrm{w}}$ values of 0.03 and $0.09 \mathrm{~mm}$ were found in groups 1 and 2, respectively, with ICC associated of 0.992 and 0.956 . This level of intrasession or intraobserver repeatability is comparable to that reported for the same and other optical biometers when used for measuring phakic eyes. ${ }^{10-12,14,21-23}$ McAlinden at al ${ }^{12}$ reported a $S_{\mathrm{w}}$ value of $0.02 \mathrm{~mm}$ 
for ACD measurements obtained with a commercially available optical lowcoherence reflectometer. $S_{\mathrm{w}}$ values of 0.03 and $0.05 \mathrm{~mm}$ were reported for ACD measurements obtained by Huang et $\mathrm{al}^{11}$ using the Aladdin system in healthy and cataract phakic eyes. As happened with AXL, a significant difference was obtained between IOL groups in terms of intrasession repeatability, with a trend to less repeatable measurements in those eyes implanted with the acrylic MI60 IOL with lower refractive index. As previously commented, the difference in refractive index between IOLs seems to be the main factor accounting for this. Although in group 2 a higher level of variability was observed in ACD repeated measurements compared to group 1, they could be considered acceptable as this variability is within a range with the potential of having a minimal impact on clinical decisions ( $\mathrm{CV}$ from 0 to $12.35 \%$ ).

In contrast to AXL and $\mathrm{ACD}$, measurements of IOLT were found to be very variable and with a poor consistency in both IOL groups. Values of $S_{\mathrm{w}}$ of 0.29 and $0.12 \mathrm{~mm}$ were found in groups 1 and 2, with ICC of 0.065 and 0.770 . This confirms that the device evaluated has a limitation for obtaining consistent measurements of IOLT. This contrasts with the good levels of repeatability reported for crystalline lens thickness measurements with different optical biometers. ${ }^{23,24}$ This may be a limitation that is present in pseudophakic eyes measured with this technology that should be investigated further. Indeed, statistically significant and clinically relevant differences have been found and reported when comparing lens thickness measurements obtained with ultrasound immersion and optical biometry. ${ }^{29}$ Besides this, in the current study, the correlation between IOL power and $S_{w}$ for each parameter evaluated was investigated, as well as the correlation between the magnitude of each parameter evaluated and its $\mathrm{S}_{\mathrm{w}}$ associated. Thus, an increased magnitude of an anatomical variable or a higher or lower IOL power implanted was confirmed if it was associated 
to higher levels of intrasession error. Specifically, a statistically significant and positive correlation was found between the magnitude of IOLT and its $\mathrm{S}_{\mathrm{w}}$. This reveals that there was a trend to a higher variability of IOLT measurements in those pseudophakic eyes implanted with thicker IOLs. This poor consistency of IOLT measurements with the technology used must be investigated in detail in order to find the limitation in the measuring procedure and optical principles leading to this situation.

In conclusion, the optical biometer based on optical low-coherence interferometry Aladdin provides consistent measurements of AXL and ACD in pseudophakic eyes implanted with IOLs of two different refractive indexes. However, there is a limitation in the consistency of IOLT measurements that should be investigated further in order to develop optimizations allowing to overcome it. 


\section{References}

1.- Lam AK, Chan R, Pang PC. The repeatability and accuracy of axial length and anterior chamber depth measurements form the IOL Master. Ophthalmic Physiol Opt 2001; 21: 477-83.

2.- Connors R 3rd, Boseman P 3rd, Olson RJ. Accuracy and reproducibility of biometry using partial coherence interferometry. J Cataract Refract Surg 2002; 28 : $235-8$

3.- Santodomingo-Rubido J, Mallen EA, Gilmartin B, Wolffsohn JS. A new noncontact optical device for ocular biometry. Br J Ophthalmol 2002; 86: 458-62.

4.- Eleftheriadis H. IOLMaster biometry: refractive results of 100 consecutive cases. Br J Ophthalmol 2003; 87: 960-3.

5.- Chen YA, Hirnschall N, Findl O. Evaluation of 2 new optical biometry devices and comparison with the current gold standard biometer. J Cataract Refract Surg $2011 ; 37: 513-7$.

6.- Savini G, Negishi K, Hoffer KJ, Lomoriello DS. Refractive outcomes of intraocular lens power calculation using different corneal power measurements with a new optical biometer. J Cataract Refract Surg 2018; 44: 701-708.

7.- Hoffer KJ, Shammas HJ, Savini G. Comparison of 2 instruments for measuring axial length. J Cataract Refract Surg 2010; 36: 644-648.

8.- Hoffer KJ, Hoffmann PC, Savini G. Comparison of a new optical biometer using swept-source optical coherence tomography and a biometer using optical lowcoherence reflectometry. J Cataract Refract Surg 2016; 42: 1165-1172. 
9.- Ventura BV, Ventura MC, Wang L, Koch DD, Weikert MP. Comparison of biometry and intraocular lens power calculation performed by a new optical biometry device and a reference biometer. J Cataract Refract Surg 2017; 43: 74-79.

10.- Mandal P, Berrow EJ, Naroo SA, Wolffsohn JS, Uthoff D, Holland D, Shah S. Validity and repeatability of the Aladdin ocular biometer. Br J Ophthalmol 2014; 98: 256-258.

11.- Huang J, Savini G, Wu F, Yu X, Yang J, Yu A, Yu Y, Wang Q. Repeatability and reproducibility of ocular biometry using a new noncontact optical low-coherence interferometer. J Cataract Refract Surg 2015; 41: 2233-2241.

12.- McAlinden C, Gao R, Yu A, Wang X, Yang J, Yu Y, Chen H, Wang Q, Huang J. Repeatibility and agreement of ocular biometry measurements: Aladdin versus Lenstar. Br J Ophthalmol 2017; 101: 1223-1229.

13.- Hoffer KJ, Shammas HJ, Savini G, Huang J. Multicenter study of optical low coherence interferometry and partial-coherence interferometry optical biometers with patients from the United States and China. J Cataract Refract Surg 2016; 42: 62-7.

14.- Sabatino F, Findl O, Maurino V. Comparative analysis of optical biometers. J Cataract Refract Surg 2016; 42: 685-93.

15.- Sorkin N, Rosenblatt A, Barequet IS. Predictability of biometry in patients undergoing cataract surgery. Optom Vis Sci 2016; 93: 1545-1551.

16.- Ruiz-Belda C, Rodrigo F, Piñero DP. Validation of keratometric measurements obtained with an intraoperative image-guided system: intra-session repeatability and interchangeability with an optical biometer. Clin Exp Optom 2018; 101: 200-205.

17.- Luft N, Hirnschall N, Farrokhi S, Findl O. Comparability of anterior chamber depth measurements with partial coherence interferometry and optical low-coherence reflectometry in pseudophakic eyes. J Cataract Refract Surg 2015; 41: 1678-84. 
18.- Nemeth G, Vajas A, Kolozsvari B, Bertha A, Modis L Jr. Anterior chamber depth measurements in phakic and pseudophakic eyes: Pentacam versus ultrasound device. J Cataract Refract Surg 2006; 32: 1331-5.

19.- Zhang Q, Jin W, Wang Q. Repeatability, reproducibility, and agreement of central anterior chamber depth measurements in pseudophakic and phakic eyes: optical coherence tomography versus ultrasound biomicroscopy. J Cataract Refract Surg 2010; 36: 941-6.

20.- Su PF, Lo AY, Hu CY, Chang SW. Anterior chamber depth measurement in phakic and pseudophakic eyes. Optom Vis Sci 2008; 85: 1193-200.

21.- Hassan AH, Sayed KM, ElAgooz M, Elhawary AM. Refractive results: safety and efficacy of secondary piggyback Sensar ${ }^{\mathrm{TM}}$ AR40 intraocular lens implantation to correct pseudophakic refractive error. J Ophthalmol 2016; 2016: 4505812.

22.- Jin H, Rabsilber T, Ehmer A, Borkenstein AF, Limberger IJ, Guo H, Auffarth GU. Comparison of ray-tracing method and thin-lens formula in intraocular lens power calculations. J Cataract Refract Surg 2009; 35: 650-62.

23.- Martínez-Albert N, Esteve-Taboada JJ, Montés-Micó R, Fernández-Vega-Cueto L, Ferrer-Blasco T. Repeatability assessment of biometric measurements with different refractive states and age using a swept-source biometer. Expert Rev Med Devices 2019; 16: 63-69.

24.- Hua Y, Qiu W, Xiao Q, Wu Q. Precision (repeatability and reproducibility) of ocular parameters obtained by the Tomey OA-2000 biometer compared to the IOLMaster in healthy eyes. PLoS One 2018; 13: e0193023.

25.- Ruiz-Mesa R, Abengózar-Vela A, Ruiz-Santos M. Comparison of a new Scheimpflug imaging combined with partial coherence interferometry biometer and a low-coherence reflectometry biometer. J Cataract Refract Surg 2017; 43: 1406-1412. 
26.- Kim S, Na J, Kim MJ, Lee BH. Simultaneous measurement of refractive index and thickness by combining low-coherence interferometry and confocal optics. Opt Express 2008; 16: 5516-26.

27.- Ohmi M, Ohnishi Y, Yoden K, Haruna M. In vitro simultaneous measurement of refractive index and thickness of biological tissue by the low coherence interferometry. IEEE Trans Biomed Eng 2000; 47: 1266-70.

28.- Faria-Ribeiro M, Lopes-Ferreira D, López-Gil N, Jorge J, González-Méijome JM. Errors associated with IOLMaster biometry as a function of internal ocular dimensions. J Optom 2014; 7: 75-8.

29.- Savini G, Hoffer KJ, Schiano-Lomoriello D. Agreement between lens thickness measurements by ultrasound immersion biometry and optical biometry. J Cataract Refract Surg 2018; 44: 1463-1468. 
Table 1.- Main clinical characteristics of patients included in the two groups of the current study.

\begin{tabular}{|c|c|c|c|}
\hline $\begin{array}{c}\text { Mean (SD) } \\
\text { Median (Range) }\end{array}$ & Group 1 & Group 2 & P-value \\
\hline Age (years) & $\begin{array}{c}71.1(7.4) \\
71.0(51 \text { to } 85)\end{array}$ & $\begin{array}{c}73.7(8.4) \\
73.0(59 \text { to } 92)\end{array}$ & 0.179 \\
\hline $\begin{array}{c}\text { Male/Female } \\
\text { (\%) }\end{array}$ & $37.1 / 62.9 \%$ & $61.8 / 38.2 \%$ & \\
\hline $\begin{array}{c}\text { Right/left eye } \\
\text { (\%) }\end{array}$ & $48.6 / 51.4 \%$ & $50.0 / 50.0 \%$ & 0.906 \\
\hline AXL (mm) & $\begin{array}{c}22.97(1.21) \\
22.77(20.84 \text { to } \\
26.48)\end{array}$ & $\begin{array}{l}23.25(1.04) \\
23.07(21.51 \text { to } \\
25.48)\end{array}$ & 0.318 \\
\hline $\begin{array}{c}\text { Preoperative } \\
\text { AXL (mm) }\end{array}$ & $\begin{array}{c}23.07(1.24) \\
22.85(20.94 \text { to } \\
26.62) \\
\text { Pre-post } \mathrm{p}<0.001\end{array}$ & $\begin{array}{c}23.35(1.05) \\
23.16(21.65 \text { to } \\
25.66) \\
\text { Pre-post } \mathrm{p}<0.001\end{array}$ & 0.298 \\
\hline ACD (mm) & $\begin{array}{c}4.53(0.37) \\
4.51(3.73 \text { to } \\
5.34)\end{array}$ & $\begin{array}{c}5.50(0.33) \\
5.43(4.84 \text { to } 6.28)\end{array}$ & $<0.001$ \\
\hline IOLT (mm) & $\begin{array}{c}0.71(0.14) \\
0.71(0.41 \text { to } \\
1.19)\end{array}$ & $\begin{array}{c}0.50(0.57) \\
0.31(0.01 \text { to } 1.97)\end{array}$ & $<0.001$ \\
\hline IOL power (D) & $\begin{array}{c}21.89(3.53) \\
22.00(10.50 \text { to } \\
28.00)\end{array}$ & $\begin{array}{c}21.88(2.39) \\
22.25(16.00 \text { to } \\
26.50)\end{array}$ & 0.996 \\
\hline
\end{tabular}

Abbreviations: SD, standard deviation; D, diopter; AXL, axial length; ACD, anterior chamber depth; IOLT, central thickness of the intraocular lens; IOL, intraocular lens. 


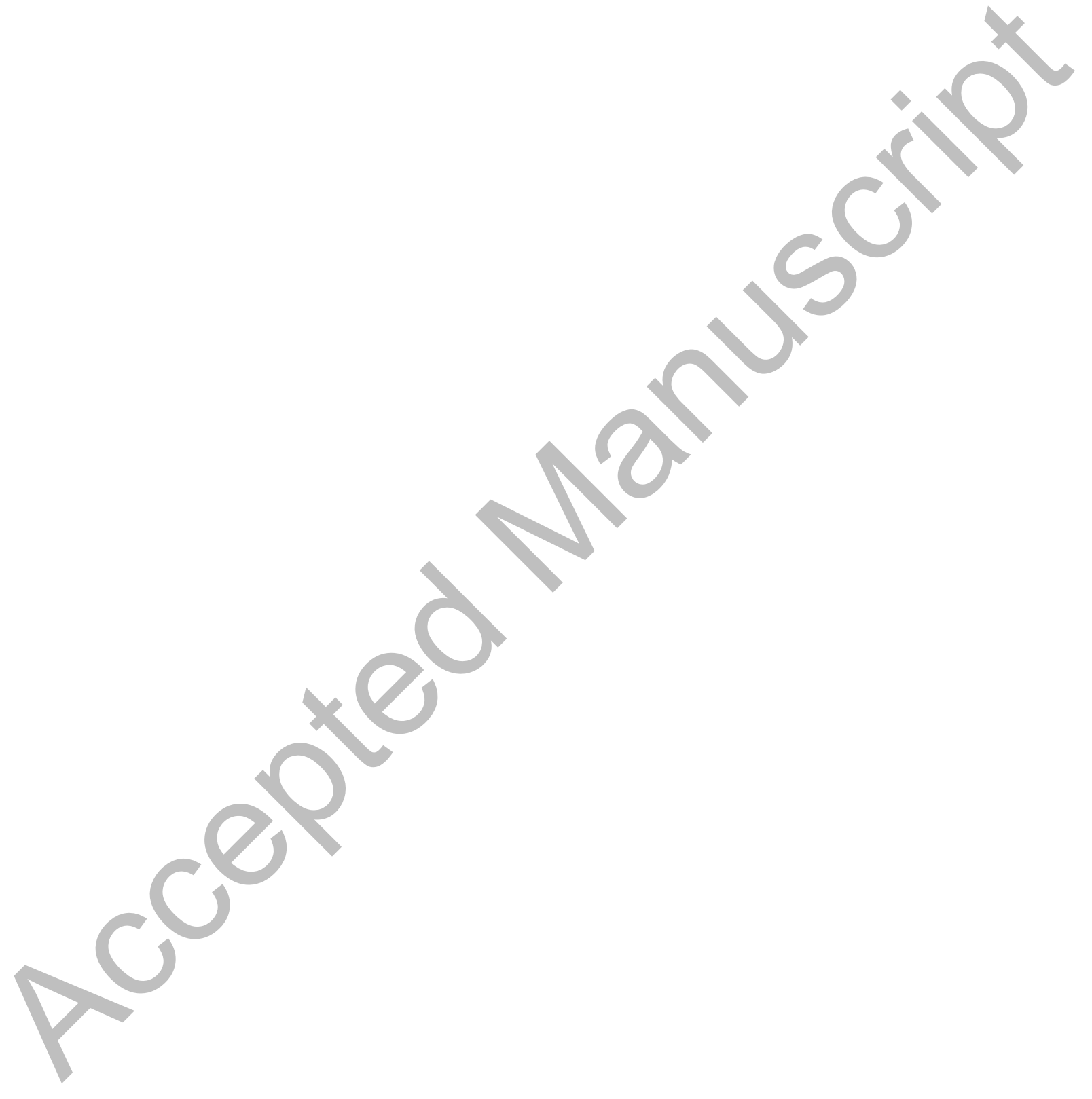


Table 2.- Intrasession analysis of pseudophakic axial length, anterior chamber depth and IOl thickness in the two groups of the current study.

\begin{tabular}{|c|c|c|c|}
\hline & Group 1 & Group 2 & p-value \\
\hline & \multicolumn{2}{|c|}{ Pseudophakic AXL (mm) } & \\
\hline \multirow{3}{*}{$\begin{array}{c}S_{\mathrm{w}}(\mathrm{SD}) \\
\text { Median (Range) }\end{array}$} & $0.03(0.03)$ & $0.05(0.04)$ & \multirow[t]{3}{*}{0.024} \\
\hline & $0.03(0.01$ to & $0.04(0.01$ to 0.18$)$ & \\
\hline & $0.14)$ & & \\
\hline \multirow{3}{*}{$\begin{array}{c}\text { Intrasubject } \\
\text { precision (mm) } \\
\text { Median (Range) }\end{array}$} & $0.07(0.06)$ & $0.10(0.07)$ & \multirow[t]{3}{*}{0.024} \\
\hline & $0.05(0.01$ to & $0.08(0.02$ to 0.36$)$ & \\
\hline & $0.28)$ & & \\
\hline \multirow[t]{3}{*}{ CV (\%) } & $0.14(0.12)$ & $0.22(0.16)$ & \multirow[t]{3}{*}{0.031} \\
\hline & $0.10(0.03$ to & $0.18(0.05$ to 0.83$)$ & \\
\hline & $0.63)$ & & \\
\hline ICC & 1.000 & 0.999 & \\
\hline$(95 \% \mathrm{CI})$ & (0.999 to 1.000$)$ & (0.998 to 0.999$)$ & \\
\hline \multirow{4}{*}{\multicolumn{4}{|c|}{$\begin{array}{c}\text { Mean difference (SD) } \\
\text { Measures 1-2 }\end{array}$}} \\
\hline & & & \\
\hline & & & \\
\hline & & & \\
\hline LoA & & & \\
\hline Measures 1-2 & -0.12 to 0.16 & -0.17 to 0.17 & \\
\hline Measures 1-3 & -0.07 to 0.13 & -0.10 to 0.14 & \\
\hline Measures 2-3 & -0.10 to 0.10 & -0.14 to 0.22 & \\
\hline & \multicolumn{2}{|c|}{ Pseudophakic ACD ( $\mathrm{mm})$} & \\
\hline$S_{w}(S D)$ & $0.03(0.04)$ & $0.09(0.15)$ & 0.011 \\
\hline Median (Range) & $0.02(0.00$ to & $0.04(0.00$ to 0.66$)$ & \\
\hline & $0.25)$ & & \\
\hline Intrasubject & $0.05(0.08)$ & $0.19(0.30)$ & 0.011 \\
\hline precision (mm) & 0.03 (0.00 to & $0.07(0.00$ to 1.29$)$ & \\
\hline Median (Range) & $0.49)$ & & \\
\hline CV (\%) & $0.55(0.87)$ & $1.75(2.86)$ & 0.021 \\
\hline & $0.35(0.00$ to & $0.58(0.00$ to & \\
\hline
\end{tabular}




\begin{tabular}{|c|c|c|c|}
\hline & 5.19) & 12.35) & \\
\hline $\begin{array}{c}\text { ICC } \\
(95 \% \mathrm{CI})\end{array}$ & $\begin{array}{c}0.992 \\
\text { (0.986 to } 0.996)\end{array}$ & $\begin{array}{c}0.956 \\
(0.910 \text { to } 0.980)\end{array}$ & \\
\hline Mean difference (SD) & & & \\
\hline Measures 1-2 & $0.02(0.08)$ & $0.07(0.17)$ & \\
\hline Measures 1-3 & $0.00(0.03)$ & $0.06(0.13)$ & \\
\hline Measures 2-3 & $-0.01(0.08)$ & $-0.06(0.25)$ & \\
\hline LoA & & & \\
\hline Measures 1-2 & -0.14 to 0.18 & -0.26 to 0.40 & \\
\hline Measures 1-3 & -0.06 to 0.06 & -0.19 to 0.31 & \\
\hline Measures 2-3 & -0.17 to 0.15 & -0.55 to 0.43 & \\
\hline & IOLT & $(\mathrm{mm})$ & \\
\hline $\begin{array}{c}S_{\mathrm{w}}(\mathrm{SD}) \\
\text { Median (Range) }\end{array}$ & $\begin{array}{c}0.12(0.14) \\
0.06(0.01 \text { to } \\
0.52)\end{array}$ & $\begin{array}{c}0.29(0.31) \\
0.28(0.00 \text { to } 1.15)\end{array}$ & 0.008 \\
\hline $\begin{array}{c}\text { Intrasubject } \\
\text { precision (mm) } \\
\text { Median (Range) }\end{array}$ & $\begin{array}{c}0.24(0.27) \\
0.12(0.01 \text { to } \\
1.03)\end{array}$ & $\begin{array}{c}0.57(0.61) \\
0.55(0.00 \text { to } 2.25)\end{array}$ & 0.008 \\
\hline CV (\%) & $\begin{array}{c}20.84(31.39) \\
8.22(0.79 \text { to } \\
127.62)\end{array}$ & $\begin{array}{c}62.39(39.96) \\
52.04(0.00 \text { to } \\
159.64)\end{array}$ & 0.368 \\
\hline $\begin{array}{c}\text { ICC } \\
(95 \% \mathrm{CI})\end{array}$ & $\begin{array}{c}0.065 \\
(-1.158 \text { to } 0.646)\end{array}$ & $\begin{array}{c}0.770 \\
(0.027 \text { to } 0.965)\end{array}$ & \\
\hline $\begin{array}{c}\text { Mean difference (SD) } \\
\text { Measures 1-2 } \\
\text { Measures 1-3 } \\
\text { Measures 2-3 }\end{array}$ & $\begin{array}{l}0.04(0.22) \\
-0.08(0.23) \\
-0.07(0.31)\end{array}$ & $\begin{array}{l}0.00(0.39) \\
0.49(0.91) \\
0.25(1.01)\end{array}$ & \\
\hline $\begin{array}{c}\text { LoA } \\
\text { Measures 1-2 } \\
\text { Measures 1-3 } \\
\text { Measures 2-3 }\end{array}$ & $\begin{array}{l}-0.39 \text { to } 0.47 \\
-0.53 \text { to } 0.37 \\
-0.68 \text { to } 0.54\end{array}$ & $\begin{array}{l}-0.76 \text { to } 0.76 \\
-1.29 \text { to } 2.27 \\
-1.73 \text { to } 2.23\end{array}$ & \\
\hline
\end{tabular}


Abbreviations: SD, standard deviation; AXL, axial length; ACD, anterior chamber depth; IOLT, intraocular lens thickness; $\mathrm{S}_{\mathrm{w}}$, within-subject standard deviation; ICC, intraclass correlation coefficient; CV, coefficient of variation; CI, confidence interval; IOL, intraocular lens; LoA, limits of agreement. 